\title{
nature
}

\section{Games people play with authors' names}

Authorship of a scientific paper is a privilege that is all too easily abused. Attempts to solve the problem with general rules encounter insurmountable obstacles, but individual accountability is unavoidable.

$\mathrm{n}$ one respect at least, artists are to be envied by scientists. Artists may lack the benefit of science's capacity for objective certainty and the immediate recognition of worth that usually comes with it; they may lack the technological relevance that stimulates large investment; and they tend to lack the relative security of an employment contract. But they can generally take for granted what for a scientist is an increasingly rare privilege: being the sole originator of his or her creation. A corollary is that the artist is released from one burden in particular: the bitterness that can arise in scientific collaboration. And nothing is more likely to be divisive than the list of a scientific paper's authors. Do we therefore need more rules of conduct?

Few would dispute that researchers have to take responsibility for papers that have their names on them. A senior laboratory figure who puts his or her name on a paper without direct supervision or involvement is unquestionably abusing the system of credit. There have been occasions where distinguished scientists have put their names irresponsibly on a paper that has turned out to contain serious errors or fraud. Rightly, some of them have paid a heavy price. But how deeply does a principal investigator or supervisor have to be aware of details of a paper bearing their names?

\section{Definition}

One response might be a general rule that any co-author should be able to take responsibility for the entire content of a paper. Although that seems reasonable at first sight, it will often fly in the face of practicality, as when an identification of a new hominid depends on the bringing together of independent and specialized skills in dating, stratigraphy, morphological comparison and possibly molecular biology. The rule fails where, as is often the case, the skills and experience involved are complementary but not even contiguous, let alone overlapping. That gives rise to another twist to the debate: if the dating, although essential to the conclusions, is done blind - in other words, without reference to the context of the samples - do the daters deserve more than an acknowledgement? Many would say not.

An alternative and less demanding definition, then, of the threshold for authorship might be that anybody with a name on the paper must have contributed something essential and scientifically original in arriving at its conclusions. But what of agreements (or attempts at them) between researchers that an inventor of an innovative new technique should be included in the authorship of a paper that involves the technique but not its originator? It is not unknown in astronomy, for example, for the inventor of an innovative detector to insist that any use of that instrument requires his name to appear on the paper. This issue has inevitably arisen more frequently in an era in which research is increasingly multidisciplinary. For example, agreements have been struck in physics laboratories to the effect that chemists who synthesize photonically interesting materials should appear only on the first physics paper to emerge and only be acknowledged thereafter. Such agreements are inevitably ad hoc.

Authorship causes trouble enough, without the added strife that arises from attempts to attribute a contribution more precisely. There was a vigorous debate recently in the Nature editorial office about whether to permit footnotes to papers indicating that authors X, Y and possibly $\mathrm{Z}$ made equal contributions to the result. The debate was split along disciplinary lines — most biologists for, physical scientists broadly against. On the principle that Nature should try to provide a service rather than a straitjacket, we decided to respond to a genuine demand apparently restricted to the biological community, hoping that physical scientists would not notice and then start worrying about the issue. So far our hope has been more or less fulfilled. But tolerance runs out when footnotes are sought not only by the first two authors but also, absurdly, by the last two as well.

\section{Responsibility}

One might speculate that physical scientists differ on this issue either because they are more mature or, more probably, because they are in less cut-throat areas of research. Certainly they seem more readily to opt for a rational if somewhat impersonal approach: alphabetical listing. High-energy physicist collaborations, notoriously extended, may start the listing with one or two key individuals and will then list alphabetically. One worried author in a less hyper-collaborative branch of the physical sciences went so far as to survey three hundred papers in physics, mathematics and chemistry having two authors, to discover that three-quarters of them had names in alphabetical order. His null hypothesis was that one half had made a conscious decision to list themselves alphabetically (and that the practice appears to be universal in mathematics).

Alphabetical ordering reduces scope for debates about credit, but not recognition: one cannot escape the fact that $\mathrm{K}$. Aa, the scientist whose name happens to appear first in the 1996 Science Citation Indexlisting, has a particular advantage in this respect. That, presumably, is why some long-standing collaborations list themselves alphabeti-cally but in rotation.

There are places where quantification of research assessment has run amok, to the extent that individuals are even rated according to their position on author lists. Such schemes are fatally undermined not least by the fact that particularly distinguished authors may put themselves last on some occasions, penultimately when they wish to give a colleague a leg-up by donating the supposedly privileged last slot, or even first if, selfishly, they can enforce their will over more deserving colleagues when a paper is expected to be much cited.

The conclusion? Attempts to produce even quite simple rules about the deployment of authors' names are doomed to fail at the inevitable emergence of counter-examples. Nevertheless it remains the case that having one's name on a paper must be an acceptance of personal responsibility, a betrayal of which can damage people's trust not only in an individual but also in science itself. 